
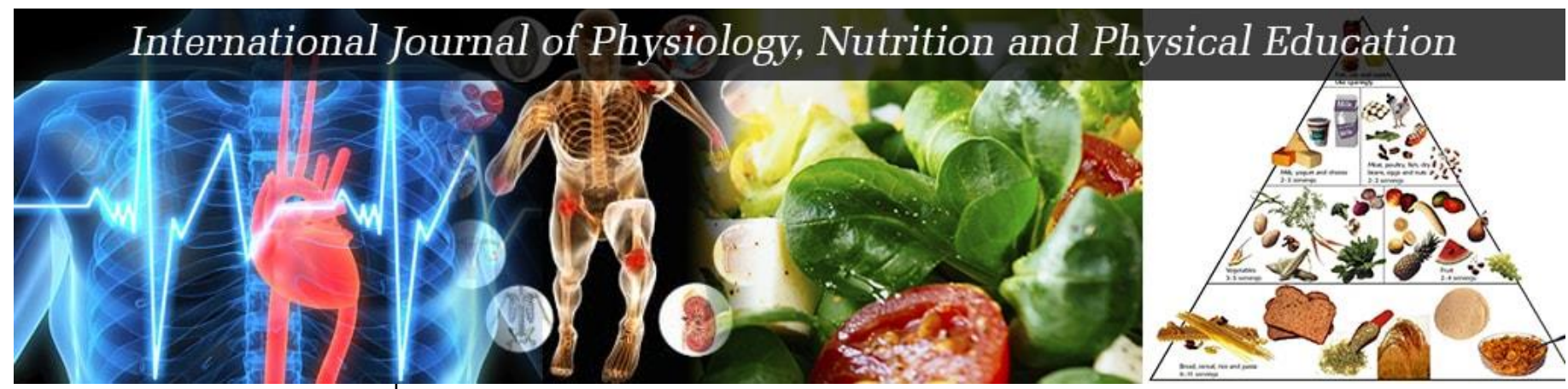

ISSN: $2456-0057$

IJPNPE 2021; 6(1): 99-102

(C) 2021 IJPNPE

www.journalofsports.com

Received: 22-11-2020

Accepted: 24-12-2020

\section{A Amrutha}

Ph.D. Scholar, Centre for Yoga Studies, Annamalai University, Chidambaram, Tamil Nadu, India

\section{Dr. S Alagesan}

Associate Prof, Dept. of Physical

Education, Annamalai

University, Chidambaram,

Tamil Nadu, India
Corresponding Author:

A Amrutha

Ph.D. Scholar, Centre for Yoga Studies, Annamalai University, Chidambaram, Tamil Nadu,

India

\section{Effect of alternate nostril breathing and meditation practices on stress and aggression among the university women students}

\section{A Amrutha and Dr. S Alagesan}

DOI: https://doi.org/10.22271/journalofsport.2021.v6.i1b.2188

\section{Abstract}

Yoga is an effective complementary approach to health maintenance and promotion for College women and has been demonstrated to support many dimensions of psychological wellbeing, from everyday stress to anxiety, aggression, and coping with health challenges. The Purpose of the present investigation was to find out the effect of Alternate Nostril Breathing and Meditation practices on psychological variables (stress and aggression). To achieve this purpose, 45 women students were selected randomly as subjects from various department from Annamalai university, Annamalai Nagar, Chidambaram. And their age between 18 to 25 years. They were divided into three equal groups namely Alternate Nostril Breathing practices group, Meditation practices group and control group. The Alternate Nostril Breathing practices group and Meditation groups did train for all Six weeks. The pre and post test were taken for all subjects before and after the training, respectively. The data pertaining to the variables in this were examined by using dependent T- test and analysis of covariance (ANCOVA). The six weeks of Alternate Nostril Breathing practices group and Meditation practices group practices on psycho logical variables improved the among the students.

Keywords: pranayama, Nadi shodhana pranayama, alternate nostril breathing, meditation, stress, aggression, yoga

\section{Introduction}

Yoga is the art and science of living and is concerned with the evolution of mind and body. It is a form of complete education that can be used on all because it develops physical stamina, emotional stability, and intellectual and creative talents. It is a unified system for developing a total and balanced personality. Yoga is basically a method by which the transmission of energies in the physical, mental, intellectual, and spiritual bodies are synchronized and optimized. Many complementary and alternative medicine (CAM) users implement these approaches, at least in part, for the management of disorders that are either psychological or stress related. Medical professionals may be able to recommend yoga to support self-care as part of a wider treatment plan, particularly in women who would be resistant to other psychological interventions. Yoga practice provides an alternate option for general practitioners to offer their women patients who experience mild psychological distress.

Charles Leadbeater, a Theosophical Society patriarch, wrote the first experiential account of the cakras by a Westerner. The influx of Indian Yoga and meditation teachers and teachings to the West, particularly since the late 1960s, has furthered the spread of experiences with and writings about the cakras.

The Hindu system describes seven major cakras in the following locations: first (base of the spine), second (sexual organs), third (solar plexus), fourth (center of the chest), fifth (midthroat), sixth (between and slightly above the eyebrows), and seventh (top of the head).

Knowledge of and experience with the cakras help to bridge psychology and spirituality, enriching our understanding of transpersonal psychotherapy and helping to ground it in the body. 


\section{Influence of Pranayama and Meditation on Psychological Health}

Traditional yoga philosophy points to key mechanisms for yoga's mental health benefits. First is mindfulness, the practice of complete present-moment awareness. During pranayama and meditation practice, one is encouraged to focus on breath, sensation, and mindful movement, rather than allowing the mind to wander. Second, physiology of Autonomic Nervous System of nostril breathing practices and its probable relation with nostril and cerebral dominance. Kayser, renowned rhinologist defined nasal cycle as a phenomenon of the alternating congestion, decongestion response of erectile tissue of nasal turbinate and septum of two nostrils, which effectively altered the unilateral nasal resistance and was existent on account of prevailing sympathetic or parasympathetic tone.

Nadi shodhana pranayama or Alternate nostril breathing is one of the most necessary practices on the path of yoga. Due to its various stages and ratios of inhalation to exhalation, it is also suitable for most people.

The practice of Alternate Nostril Breathing the correct breathing technique helps to manipulate our energies. Most of us breathe incorrectly, using only half of our lung capacity. Pranayama is a technique, which re-educates our breathing process, helps us to release tensions and develop a relaxed state of mind. It also balances autonomic nervous system and encourages creative thinking. In addition, by increasing the amount of oxygen to our brain it improves mental clarity, alertness and physical well being.

Due to our hectic and stressful life, this naturally occurring alternate breathing cycle gets disrupted and we suffer from different ailments. And these ailments are due to imbalance of functions of autonomic nervous system and can be resolved by practicing alternate nostril breathing (Nadisodhana pranayama).

Meditation practice supports internal focus, increased selfcontrol, and mindful acceptance. For instance, learning to focus on the breath may provide a simple practice that supports learning to cultivate attentional focus.

\section{Methodology}

The investigator selected 45 women students randomly from various department of Annamalai university, Annamalai Nagar, Chidambaram and their age were between 18 to 25 years. Selected subjects were divided into three groups. The experimental group I underwent Alternate Nostril Breathing and group II Meditation practices weekly five days i.e., Monday to Friday, between $6.00 \mathrm{pm}$ to $7.00 \mathrm{pm}$ for a period of six weeks, and group III not practicing Alternate Nostril Breathing and Meditation. Stress and Aggression were selected as criterion variables all the subjects were tested at prior and immediately after the training period on selected dependent variable. The collected data was analyzed statistically by using analysis covariance (ANCOVA) to find out the significant differences if any between the groups at before and immediately after the training period on selected dependent variable separately. In all cases, .05 level of confidence was fixed to test the significance.

\section{Analysis of Data \\ Results on Stress}

The data on the effect of Alternate Nostril Breathing practices and Meditation practices on psychological variable, stress was collected through pre and post test scores and subjected to statistical treatment using ANCOVA. Table 1 shows the results obtained.

Table 1: Computation of Analysis of Covariance of Stress (Scores in numbers)

\begin{tabular}{|c|c|c|c|c|c|c|c|c|}
\hline Means & $\begin{array}{c}\text { Alternate Nostril } \\
\text { Breathing Group }\end{array}$ & $\begin{array}{c}\text { Meditation } \\
\text { Group }\end{array}$ & $\begin{array}{c}\text { Control } \\
\text { Group }\end{array}$ & $\begin{array}{c}\text { Source of } \\
\text { Squares }\end{array}$ & $\begin{array}{c}\text { Sum of } \\
\text { squares }\end{array}$ & DF & $\begin{array}{c}\text { Mean } \\
\text { squares }\end{array}$ & Obtained \\
\hline Pre test & 53.73 & 53.47 & 52.53 & $\begin{array}{c}\text { Between } \\
\text { Within }\end{array}$ & $\begin{array}{c}5.0 \\
1579.6\end{array}$ & $\begin{array}{c}2 \\
42\end{array}$ & $\begin{array}{c}2.49 \\
37.61\end{array}$ & 0.07 \\
\hline Post test & 61.73 & 62.40 & 53.73 & $\begin{array}{c}\text { Between } \\
\text { Within }\end{array}$ & $\begin{array}{c}912.2 \\
910.3\end{array}$ & $\begin{array}{c}2 \\
42\end{array}$ & $\begin{array}{c}456.09 \\
21.67\end{array}$ & 21.04 \\
\hline Adjusted & 62.63 & 61.79 & 52.25 & $\begin{array}{c}\text { Between } \\
\text { within }\end{array}$ & $\begin{array}{c}994.9 \\
255.5\end{array}$ & $\begin{array}{c}2 \\
41\end{array}$ & $\begin{array}{c}497.44 \\
6.23\end{array}$ & 79.83 \\
\hline Mean Diff & 8.00 & 8.93 & 1.20 & & & & & \\
\hline
\end{tabular}

Table 1 shows the obtained pre test means and post test means and the adjusted means for stress. The obtained $F$ value on the scores of pre test means 0.07 was less than the required $F$ value required 3.22 , to be significant at 0.05 level This proved that the random assignment of the subjects were successful and their scores in stress before the training were equal and there was no significant differences.

The obtained $F$ value on the scores of post test means 21.04 was greater than the required $F$ value 3.22 , which proved that the interventional programmes, Alternate Nostril Breathing practices and Meditation practices were significantly influences stress of the subjects. Taking into consideration of the pre test means and post test means adjusted post test means were determined and analysis of covariance was done and the obtained $\mathrm{F}$ value 79.83 was greater than the required value of 3.22 and hence it was accepted that the Alternate Nostril Breathing practices and Meditation practices significantly influenced stress of the subjects. Since significant differences were recorded, the results were subjects to post hoc analysis using Scheffe's Confidence Interval test. The results were presented in Table 2.

Table 2: Scheffe's Confidence Interval Test Scores on Stress (Scores in numbers)

\begin{tabular}{|c|c|c|c|c|}
\hline Alternate Nostril Breathing & Meditation & Control & Mean Difference & Required C.I. \\
\hline 62.63 & 61.79 & & 0.84 & 2.29 \\
\hline 62.63 & & 52.25 & 10.38 & 2.29 \\
\hline & 61.79 & 52.25 & 9.54 & 2.29 \\
\hline
\end{tabular}

*Significant 
Table 2 shows that there was significant differences between Meditation group and control and Alternate Nostril Breathing practices and control group. And there was no significant mean difference between Alternate Nostril Breathing practices and Meditation groups.

\section{Results of Aggression}

The data on the effect of Alternate Nostril Breathing practices and Meditation on psychological variable, aggression was collected through pre and post test scores and subjected to statistical treatment using ANCOVA. Table 3 shows the results.

Table 3: Computation of Analysis of Covariance of Aggression (Scores in numbers)

\begin{tabular}{|c|c|c|c|c|c|c|c|c|}
\hline Means & $\begin{array}{c}\text { Alternate Nostril } \\
\text { Breathing Groups }\end{array}$ & $\begin{array}{c}\text { Meditation } \\
\text { Groups }\end{array}$ & $\begin{array}{c}\text { Control } \\
\text { Groups }\end{array}$ & $\begin{array}{c}\text { Source of } \\
\text { variance }\end{array}$ & $\begin{array}{c}\text { Sum of } \\
\text { squares }\end{array}$ & DF & $\begin{array}{c}\text { Mean } \\
\text { squares }\end{array}$ & Obtained \\
\hline Pre test & 91.93 & 91.80 & 90.60 & $\begin{array}{c}\text { Between } \\
\text { Within }\end{array}$ & $\begin{array}{c}4.6 \\
3841.7\end{array}$ & $\begin{array}{c}2 \\
42\end{array}$ & $\begin{array}{c}2.29 \\
91.47\end{array}$ & 0.03 \\
\hline Post Test & 84.60 & 82.73 & 91.93 & $\begin{array}{c}\text { Between } \\
\text { Within }\end{array}$ & $\begin{array}{c}506.8 \\
3236.1\end{array}$ & $\begin{array}{c}2 \\
42\end{array}$ & $\begin{array}{c}253.42 \\
77.05\end{array}$ & 3.29 \\
\hline Adjusted & 82.59 & 84.34 & 91.00 & $\begin{array}{c}\text { Between } \\
\text { Within }\end{array}$ & $\begin{array}{c}589.3 \\
161.2\end{array}$ & $\begin{array}{c}2 \\
42\end{array}$ & $\begin{array}{c}294.63 \\
3.93\end{array}$ & 74.92 \\
\hline Mean Diff & -7.33 & -9.07 & 1.33 & & & & & \\
\hline
\end{tabular}

Table F-ratio at 0.05 level of confidence for 2 and 42 (df) = 3.22, and 41 (df) 3.23 Table 3 shows the obtained pretest means and post test means and the adjusted means for aggression. The obtained $\mathrm{F}$ value on the scores of pre test means 0.03 was less than the required $\mathrm{F}$ value required 3.22, to be significant at 0.05 level This proved that the random assignment of the subjects were successful and their scores in aggression before the training were equal and there was no significant differences. The obtained $F$ value on the scores of post test means 3.29 was greater than the required $F$ value 3.22, which proved that the interventional programmes, Alternate Nostril Breathing practices and Meditation practices were significantly influences aggression of the subjects. Taking into consideration of the pre test and post test mean adjusted post test means were determined and analysis of covariance was done and the obtained $F$ value 74.92 was greater than the required value of 3.22 and hence it was accepted that the Alternate Nostril Breathing practices and Meditation practices significantly influenced aggression of the subjects.

Since significant differences were recorded, the results were subjected to post hoc analysis using Scheffe's Confidence Interval test. The results were presented in Table 4

Table 4: Scheff's Confidence Interval Test Scores on Aggression

\begin{tabular}{|c|c|c|c|c|}
\hline Means & & & Mean Difference & Required CI \\
\hline Alternate Nostril Breathing Groups & Meditation Groups & Control & 1.75 & 1.82 \\
\hline 82.59 & & 91.00 & 8.40 & 1.82 \\
\hline & 84.34 & 91.00 & 6.66 & 1.82 \\
\hline
\end{tabular}

* Significant

Table 4 shows that there were significant differences between Meditation group and control group and Alternate Nostril Breathing practices and control group. And there was no significant mean difference between Alternate Nostril Breathing practices and Meditation groups.

\section{Discussion of Findings}

The results on psychological variable stress were presented in Table 1 proved that there were significant differences among the post means and adjusted means between Alternate Nostril Breathing practices, Meditation and control group. The obtained $F$ values of 21.04 for post test and 79.83 for adjusted means were greater than the required $F$ value of 3.22 to be significant at 0.05 level. Since there was significant effect because of the treatment, the investigator subjected the adjusted means for post hoc analysis of the means through Scheffe's Confidence Interval test. The obtained results were presented in Table 2 and the results proved that Alternate Nostril Breathing practices significantly influences the women students Stress, comparing to the control group. Comparing between Alternate Nostril Breathing practices and Meditation practices, there was no significant differences were recorded Hence, it was proved that though practices and Meditation were significantly changed the stress, there was no significant difference between practices and Meditation practices.

The results on psychological variable aggression were presented in Table 3 proved that there was significant differences among the post means and adjusted means between Alternate Nostril Breathing practices, Meditation practices and control group. The obtained F values of 3.29 for post test and 74.92 for adjusted means were greater than the required $F$ value of 3.22 to be significant at 0.05 level. Since there was significant effect because of the treatment, the investigator subjected the adjusted means for post hoc analysis of the means through Scheffe's Confidence Interval test. The obtained results were presented in Table 4 and the results proved that Alternate Nostril Breathing practices significantly influences the women student's aggression, comparing to the control group. Comparing between Alternate Nostril Breathing practices and Meditation practices, there was no significant differences were recorded Hence, it was proved that though Alternate Nostril Breathing practices and Meditation practices were significantly changed the aggression, there was no significant difference between Alternate Nostril Breathing practices and Meditation practices.

\section{Conclusions}

Yoga is an effective complementary approach to health maintenance and promotion for women and has been demonstrated to support many dimensions of psychological wellbeing, from everyday stress to anxiety, aggression, and coping with health challenges. 
Alternate Nostril Breathing practice increases lung capacity and oxygenation, which supports increased energy and alertness. For example, learning to take deep breaths by relaxing the abdominal muscles provides a strategy for stress management, especially in contrast to the shallow breathing that may occur under stress.

Alternate nostril breathing (nadi shodan) after the postures can help to cool the body and allow the lymphatic vessels to continue to empty58. It will also calm the mind by balancing the sympathetic and parasympathetic nervous systems and is a preparation for meditation.

Mindfulness (physical and mental awareness during and after postures) and meditation practices of yoga could be of benefit to the QoL of women with BCRL. Mindfulness, and the meditation practices of witnessing (antar mouna) and body stillness (kaya sthairyam), lead to internal awareness (pratyahara). Increased internal awareness can clarify personal reactions and attitudes, thereby lessening the effects of negative reactivity and may help with acceptance of the current situation. Practices such as these have been shown to improve mood, reduce stress, and improve immune function in cancer patients, as well as facilitate adaptation to a changed living circumstance. Focused meditation (dharana and dhyana), such as candle gazing (tratak), and repetition of mantra such as OM (ajapa-japa), can improve concentration, reduce stress, and remove negative thought-patterns.

The women students reported improved biopsychosocial functioning, increased awareness, the positive power of the group.

\section{References}

1. Ando M, Morita T, Akechi T, Ifuku Y. A qualitative study of mindfulness-based meditation therapy in Japanese cancer patients. Support Care Cancer 2011;19(7):929-933.

2. Arias AJ, Steinberg K, Banga A, Trestman RL. Systematic review of the efficacy of meditation techniques as treatments for medical illness. J Altern Complement Med 2006;12(8):817-832.

3. Brown RP, Gerbarg PL. Sudarshan kriya yoga breathing in the treatment of stress, anxiety, and depression. Part II. Clinical Applications and Guidelines. Journal of Alternative and Complementary Medicine. 2005b;11:711-717.

4. Chies A, Serretti A. Mindfulness-based stress reduction for stress management in healthy people: A review and meta-analysis. Journal of Alternative and Complementary Medicine 2009;15(5):593-600.

5. Carlson LE, Speca M, Patel KD, Goodey E. Mindfulnessbased stress reduction in relation to quality of life, mood, symptoms of stress and levels of cortisol, dehydroepiandrosterone sulfate (DHEAS) and melatonin in breast and prostate cancer outpatients. Psychoneuroendocrinology. 2004;29:448-474.

6. Gura ST. Yoga for stress reduction and injury prevention at work. Work: Journal of Prevention, Assessment \& Rehabilitation 2002;19:3-7.

7. Kreitzer MJ, Gross CR, Ye X, Russas V, Treesak C. Longitudinal impact of mindfulness meditation on illness burden in solid-organ transplant recipients. Progress in Transplantation 2005;15:166-172.

8. Kvillemo P, Branstrom R. Experiences of a mindfulnessbased stress-reduction intervention among patients with cancer. Cancer Nurs 2011;34(1):24-31, 66.

9. Lasater J. Living your yoga: Finding the spiritual in everyday life. Berkeley, CA: Rodmell Press 2000.

10. Leadbeater C. The Cakras (Wheaton, I11.: Theosophical Publishing House 1927.

11. Telles S, Nagarathna R, Nagendra HR. Breathing through a particular nostril can alter metabolism and autonomic activities. Indian J Physiol Pharmacol 1994;38(2):133137.

12. Telles S, Naveen KV, Manjunath NK, Haldar DK. Effects of meditation based on scientific research. Bangalore, India: SVYASA 2010.

13. Quinones N, Maquet YG, Velez DM, Lopez MA. Efficacy of a Satyananda Yoga Intervention for Reintegrating Adults Diagnosed with Posttraumatic Stress Disorder. Int J Yoga Therap 2015;25(1):89-99.

14. Wolsko PM, Eisenberg DM, Davis RD, Phillips RS. Use of mind-body medical therapies: results of a national survey. Journal of General Internal Medicine 2004;19:4350. 